\title{
El Municipio de la Coruña y su Ayuntamiento
}

\author{
El TÉRMINO MUNICIPAL
}

Situación de la ciudad.-La muy noble y muy leal ciudad de La Coruña, cabeza, fuerza, guarda, llave y antemural del Reino de Galicia -que estos son los títulos que pregonan su glorioso abolengo histórico- es la capital más importante de la Región Gallega, con una situación verdaderamente atractiva y encantadora al nivel del mar, desplegándose en un anfiteatro desde el altozano donde vigila su faro milenario. Está asentada su parte antigua en una $\mathrm{Pe}-$ nínsula famosa por su torre de Hércules "altísimo faro" en los tiempos antiguos y único romano que se conserva en el mundo, seguramente del siglo II de nuestra Era. Hay quien dice que remotamente fué una isla que se unió a tierra formando la Península, por la acumulación de arena, $y$, dada su configuración, nada tiene de particular que así sucediese, pues actualmente la parte de la Pescadería —entre la playa del Orzán y el puerto- que constituye el istmo, es una zona muy estrecha formada por una calle, y por dicho paraje lo atravesaban en algún tiempo las aguas embravecidas del Orzán.

\section{Vicisitudes de su territorio}

A último del siglo $\mathrm{x}$, posiblemente a causa de las repetidas invasiones normandas, parece que una gran parte de su población se trasladó tierra adentro, al Burgo de Faro que es el lugar de Santiago del Burgo, a seis kilómetros de la ciudad y al fondo de su ría, disminuyendo sensiblemente su población. 
Del año 1218 existe un documento importantísimo suscrito por Alfonso IX, fundador de la ciudad, concediéndole por término al Concejo de la Curunia dos leguas "in circuito ipsius ville", es decir, el dominio y jurisdicción de dos leguas en contorno, que son indudablemente sus antiguos términos, y, entre otras cosas, el uso de las aguas, madera, leñas y pastos, así como el famoso Fuero de Benavente, documento confirmado por Pedro III, Alfonso $\mathrm{X}$ y Sancho IV, los cuales se conservan en el Archivo Municipal.

Fernando III el Santo mandó al Comendador de Faro que desalojara la Puebla del Burgo, donde se refugiaran los antiguos vecinos, porque perjudicaba a la población. Enrique III seguía con la preocupación de sus antecesores, mandando que no se introdujesen ni vendiesen vinos en la Pescadería, antiguo arrabal que hoy es el centro de la ciudad sino dentro de la Villa para que ésta no se despoblase.

De antiguo es conocida una división del término municipal en la Ciudad Vieja o simplemente la Ciudad, que es la parte antigua que estuvo amurallada en la Edad Media, con sus Iglesias, edificios, Palacios, etc., del siglo xI y xII y que tenía las.puertas (hoy calles) de Aires, Real, uniéndose con el centro denominado Pescadería, donde radicaba el Comercio y la Industria del mar, la que a su vez tenía también las puertas de la torre de arriba y abajo situadas en la parte más estrecha del istmo, hoy formado por la calle de Juan de Vega, una de las más hermosas de la ciudad. Después de esto no había más que unos míseros arrabales. Hoy toda esta zona constituye la parte nueva o el Ensanche.

\section{ANEXIONES}

La ciudad propiamente dicha fué plaza fuerte hasta I868, iniciándose el 3 de octubre de 1840 , con toda solemnidad, el derribo de las murallas que separaban la Ciudad Vieja de la Pescadería, suceso que, por constituir una de las magnas aspiraciones de la población, tuvo para la ciudad una gran trascendencia, pues aquellos mezquinos arrabales se fueron convirtiendo en barrios y al propio tiempo se fueron formando en éstos arterias constituídas por núcleos de población donde se asentó la zona principal de actividad fabril e industrial integrando el Ayuntamiento que se llamó de Santa Ma- 
ría de Oza, cuya parte principal era realmente una prolongación del de La Coruña, que necesariamente tenía que ser anexionada al mismo, como se llevó a efecto por Ley de II de julio de I9ı2, comprendiendo todo el término dicho de Santa María de Oza constituído por cuatro parroquias, que se llaman Santa María de Oza, San Vicente de Elviña, San Cristóbal das Viñas y San Pedro de Visma, distando de la capital la primera dos kilómetros, tres la segunda y tercera y dos la última, y contando con una población de 3.00I, 3.964, 3.410 y 4.105 habitantes, respectivamente.

Extensión del Municipio.-Antes de efectuarse la anexión de Santa María de Oza contaba el término municipal con una extensión superficial de 7,85 kilómetros cuadrados, dimensiones que fueron aumentadas en virtud de tal unión a 34,5 kilómetros cuadrados.

Las zonas urbanas comprendidas en el casco de la población y núcleos de apreciable densidad en contacto con la misma que disponen de alcantarillado y otros servicios municipales, tienen una extensión de 330 hectáreas.

Las zonas de ensanche, casi pobladas, comprendiendo las de trazado oficial y otras formadas por iniciativa particular, miden I 30 hectáreas; I.650 hectáreas es la extensión que ocupa la zona agrícola, comprendiendo en la misma pequeñas agrupaciones de población rural.

La zona forestal, entiendo como tal las porciones arboladas de propiedad particular, como bosques de eucaliptos, pinares, sotos de castaños, árboles frutales agrupados en huertas amuralladas y árboles de sombra diseminados o alineados en los bordes de las carreteras, puede estimarse en una proporción de un siete por ciento de la extensión agrícola, o sea, i I 5,50 hectáreas.

E1 resto del territorio, o sean, I.224,50 hectáreas, está formado por montes de poca importancia y altura con suave declive y que produce pastos y tojo de gran utilidad, como complemento agrícola, siendo insignificante la proporción de terreno improductivo, correspondiendo éste a las faldas del monte rocoso frontero al mar y combatido por los fuertes vientos del Atlántico.

Población.-Ya se indica anteriormente cómo a últimos del siglo $\mathrm{x}$ se despobló casi toda la ciudad para irse a la Puebla del Burgo; posteriormente se sabe que a comienzos del siglo xvi tenía la ciudad de La Coruña 450 vecinos pecheros.

Es de señalar que, según consta por correspondiente Libro de 
Acuerdos, la epidemia, la guerra de Flandes, las turbulencias en España y Portugal y otras calamidades repercutieron de tal manera en esta ciudad, que obligaron al Concejo a mandar el Síndico a la Corte "en busca de remedio a tanta desgracia" en $1575^{\circ}$.

En 1646 ascendían a 1.309 los vecinos y en 1657 aparece con 1.583 .

Los datos son deficientes, pues no figuraban los eclesiásticos ni los nobles, ni los exentos, siendo, por decirlo así, contribuyentes todos los registrados.

Por un manifiesto con motivo de una cuestión de la Colegiata se desprende que en I7I9 eran los vecinos unos 6.506, que en unión de las fuerzas de la guarnición ascendían a 27.012 almas. Bajó luego este número y en 1748 aparecen sólo 1.926 vecinos, efecto, sin duda, de la emigración a América. En I804 se notó nuevamente el crecimiento, pues cuenta con $3.07 \mathrm{I}$ vecinos, cifra que perdura en I820, pero que baja a 2.514 en 1835 , logrando recuperar en un año la anterior suma, pues en 1836 hay ya 3.026 vecinos.

En el año 1842 ascendía la población a 19.4I5 almas. En 1860 es 27.354 . En $1872,28.298$. Son 39.609 almas las que poblaban la ciudad en I889, y 40.50I las que había en 1897 .

En 1900 asciende la población a 43.97I habitantes; en I9ro a 45.989; en I9I7 a 44.326 habitantes, notándose un descenso bastante considerable en esta fecha, porque hay que tener en cuenta que ya comprende los habitantes del antiguo Ayuntamiento de Santa María de Oza, anexionado a La Coruña y que pudieran ser aproximadamente 9.000 habitantes, creyendo que ésta y otras oscilaciones obedecieron a la emigración.

En el año I920 son ya.62.022 los habitantes; en 1930, 74. I32, $y$ en el censo de 1940 arroja el siguiente resultado:

Población: Derecho, 98.834 habitantes. Hecho, I04.220 habitantes.

$\mathrm{Y}$, por último, en la rectificación ya aprobada de 1943 , asciende la población de: Derecho, IOI.423 habitantes; Hecho, I I0.070 habitantes.

Como se puede observar es asombroso el crecimiento de la población en lo que va de siglo, cifrándose en 137 por I00, superior en mucho al de Barcelona y Madrid, y con frecuencia nos hemos preguntado a qué puede ser debido el mismo, ya que no ha habido agregaciones de Municipios importantes ni se han creado nuevas 
industrias que hayan empleado grandes contingentes de obreros. Creemos que entre los varios factores influyentes se pueden contar los siguientes:

a) La tendencia general de la despoblación del núcleo rural y su atracción por la ciudad, tratándose del elemento obrero como de pequeños rentistas, que disfrutan así más de sus ahorros.

b) La restricción de la emigración.

c) La dulzura de su clima, carácter afable de sus habitantes, progresivo embellecimiento y comodidad de la ciudad, etc.

d) Circunstancialmente también ha contribuído a este aumento, desde el Movimiento Nacional, la instalación de la Fábrica de Armas, el aumento de la burocracia y la permanencia de bastantes familias que, refugiadas en los principios de nuestra Guerra de Liberación, aquí encontraron agradable su estancia o su modo de vivir.

\section{ACTIVIDADES ECONÓMICAS}

\section{Industrias}

La Coruña no es una población industrial; su importancia la debe, principalmente, a su puerto, a sus elementos oficiales y a su posición geográfica y dulzura de su clima.

Consignaremos respecto a su puerto, que tuvo muchísima im-portancia en épocas remotas y después durante los siglos xv, xvi y fines del xviII, preparándose y saliendo del mismo expediciones y Armadas diversas, como la célebre de las Molucas y otra para las Indias a las órdenes del Comendador García Jaspe de Loaísa, y cuando se decretó la libertad de comencio con nuestras posesiones de América, llegando a ocupar después el tercer lugar de España en el comercio de cabotaje.

Se trata de un puerto de excelentes condiciones naturales de seguridad y calado y tiene una extensión de $3.3 .50 \mathrm{~m}$. de líneas de atraque con sus servicios y utillaje, siendo acreedor a un mayor movimiento de importancia. Al amparo del puerto viven las industrias derivadas del mismo, funcionan fábricas de conservas, vive el comercio, se emplean obreros, etc.

El movimiento habido este último año, según las estadísticas de la Junta de Obras del Puerto, fué el siguiente: 


\section{Descarga :}

\begin{tabular}{lr} 
& \multicolumn{1}{c}{ Kilogramos } \\
\cline { 2 - 2 } Pescado fresco: Valor en pesetas, $45.258 .405 \ldots$. & $2 \mathrm{r} \cdot 536.507$ \\
Tráfico de bahí, cabotaje y extranjero........ & 228.329 .128 \\
\hline & 249.865 .635 \\
\hline
\end{tabular}

Embarque :

Tráfico de bahia, cabotaje y extranjero....... 252.139.573

$$
\text { Total............... } \frac{252.139 .573}{502.005 .208}
$$

Movimiento:

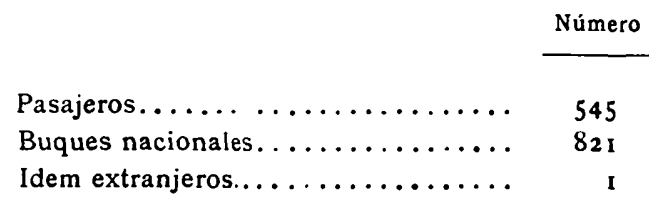

Tonelaje de los buques mercantes:



Con motivo del conflicto bélico y la restricción de carburantes se ha suprimido o restringido el movimiento de pasajeros y mercancías y las actividades portuarias, notándose incluso una disminución con relación a los años anteriores.

En La Coruña tiene su base de trabajo la flota de "bous" más numerosa del litoral español.

El tren de mar coruñés representa un capital que se aproxima a los 30 millones de pesetas.

Relacionadas con el puerto funcionan II fábricas de salazones del pescado e industrias y actividades anexas.

Merece especial mención, además, la Fábrica de Tabacos, donde se prepara toda clase de labor en picado, cigarros y preparados de rama, encontrando en ella colocación cerca de 1.000 personas, principalmente mujeres.

También es importantísima la Fábrica de Armas; funcionan- 
do, entre otras, la de cerillas, varias de aserrar maderas, de muebles, de electricidad, de tejidos e hilados, de artes gráficas, de productos químicos y farmacéuticos, sidero metalúrgicas, de productos alimenticios, una litografía muy importante, etc., manteniendo además la ciudad un comercio importantísimo y muy surtido con grandes almacenes.

\section{Actividades agrícola, Ganadera y Forestal}

Ya se indica algo al principio, en la extensión superficial del término, de lo que de él corresponde a la zona agrícola y forestal, no habiendo explotaciones mineras dentro del mismo.

En cuanto al cultivo agrícola es mixto de patata, maíz y huerta, preferentemente de secano; existen algunas praderas de regadío para ganadería estabulada, encontrándose la propiedad muy dividida, nota característica y conocida por todos. Insertamos a continuación el importe de las contribuciones, que es el siguiente:

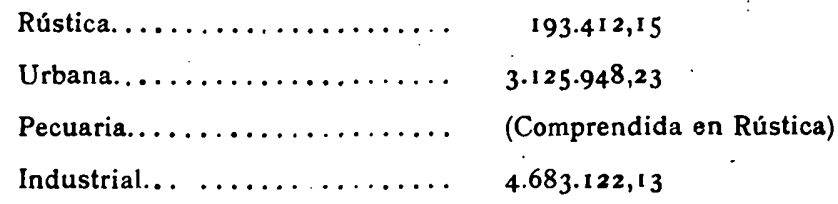

Como ya queda indicado, la extensión de la zona forestal puede estimarse en una proporción de un 7 por 100 de la extensión agrícola, siendo las especies más importantes los eucaliptos, pinos, castaños y árboles frutales, así como árboles de sombra diseminados o alineados en los bordes de las carreteras.

\section{Granjas agricolas}

Solamente existe la del Estado, instalada en terrenos de la Diputación Provincial desde el año r889, funcionando en la misma. los servicios agrícolas (estación de ensayo de semillas, estación de fitepatología, parada de sementales para ganado vacuno, lanar, de cerda y cabrío, etc.). Su extensión alcanza a I 7 hectáreas y 50 centiáreas. 
Cabezas de ganado en el término:

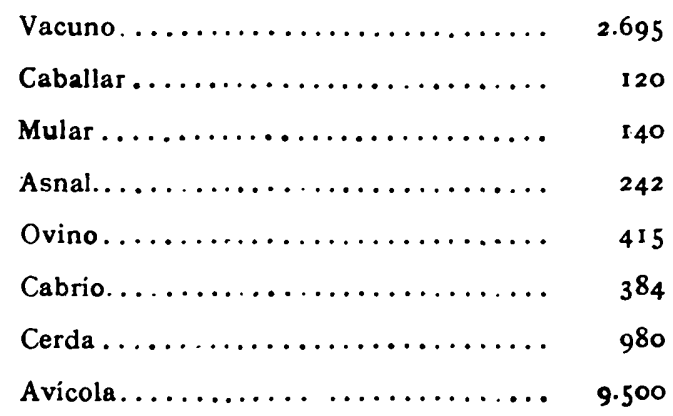

Producción agricola:

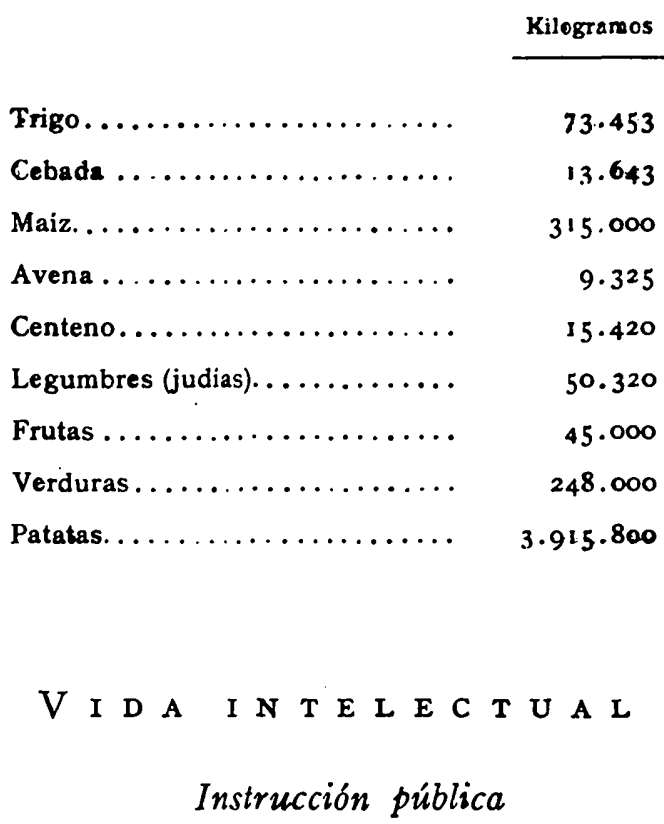

Funcionan en esta ciudad dos Institutos de Enseñanza Media, masculino y femenino, con escuela preparatoria de ingreso para niños y en vías de crearse para las niñas, y Escuela del Hogar complementaria, estando construyéndose actualmente un magnífico edificio para Instituto masculino, que será uno de los mejores de España y cuya terminación probablemente tendrá lugar este año.

1040 
También funciona una Escuela de Comercio, y contiguo al Instituto masculino en construción se está levantando nuevo edificio.

La Normal de Maestras funciona igualmente en la capital, estando aceptado un terreno para la erección de nuevo edificio en las proximidades del Instituto masculino y Escuela de Comercio citada.

Exite una Escuela Elemental del Trabajo, a cuyo edificio, en el pasado año, se levantó un piso más para la ampliación de sus servicios, y funciona igualmente otra Escuela de Artes y Oficios.

Cuenta La Coruña con 98 Escuelas Nacionales y 40 particulares, además de tres que funcionan en el Asilo Residencia Municipal y otra en el Hospicio provincial. El número de alumnos que asiste a las Escuelas Nacionales es de 5.000 y 2.500 los que van a las particulares.

Las Escuelas Graduadas -ya incluídas en el número total de Escuelas Nacionales- son tres: Grupos "Da Guarda", "Concepción Arenal" y Aneja a la Normal. Cuenta el primero de once secciones, de las cuales cuatro son de niños y siete de niñas y párvulos. El segundo tiene seis secciones de niños y seis de niñas, y la tercera nueve secciones.

Entre las escuelas particulares merece especial mención la Grande Obra de A.tocha, Institución benéfica de esta capital que presta asistencia escolar a 1.200 niños y niñas y está atendida por un grupo de más de veinte profesores de ambos sexos.

Existen, además, los Grupos escolares Curros Enríquez y Montelcet, que se hallaban al iniciarse el Movimiento, el primero en construcción y el segundo en obras de adaptación por cuenta del Estado, encontrándose en la actualidad, uno ocupado por servicios militares y otro por la Escuela de Comercio.

Emplazadas en los Centros escolares existen tres cantinas, que son: la del Magisterio primario y la de los Grupos escolares Da Guarda y Concepción Arenal y Graduada aneja a la Normal, con roperos anexos.

En el grupo de enseñanzas especiales mencionaremos el Conservatorio de Música y Declamación y la Sociedad Filarmónica.

Además de las Escuelas profesionales citadas merecen destacarse las Escuelas y Talleres de Aprendices de la Fábrica de Armas, las de Aeromodelismo del Frente de Juventudes y las del Parque de la Maestranza de Artillería de esta Región Militar. 


\section{Bibliotecas}

Existe la provincial en el Instituto de Enseñanza Media, la municipal, con su sección de infantil y general, en los jardines públicos, la del antiguo Consulado de Mar y de Comercio (de fundación particular, cuyo edificio está en obras por cuenta del Estado), la de la Real Academia Gallega, la de la Sociedad Reunión Recreativa e Instructiva de Artesanos y otras varias de menor importancia.

\section{Teatro}

El único teatro existente en La Coruña pertenece a la Beneficencia Municipal, la que lo tiene arrendado a un particular que satisface un alquiler anual de 50.000 pesetas. Durante el verano, principalmente, desfilan las primeras compañías de España, y en él dan también sus conciertos los artistas de renombre, tanto nacionales como extranjeros, presentados por la Sociedad Filarmónica de La: Coruña.

\section{Manifestaciones culturales}

Las constituyen las Exposiciones y conferencias diversas que la Asociación de Artistas de La Coruña realiza todos los años, con la admiración del público cada vez más numeroso que acude a visitarlas; las Conferencias sobre Cultura popular, etc., organizadas por la Vice-Secretaría de Educación Popular; los Cursos de Cultura Religiosa; los conciertos de la Filarmónica, y el año pasado- esperando se repitan este año- los Cursos de verano organizados por la Universidad de Santiago.

Tiene su residencia oficial en la Casa Consistorial la benemérita y antigua Real Academia Gallega, que publica un Boletín men sual de sus importantísimas actividades que abarcan todos los ramos del saber regional- Lengua, Literatura, Historia, Arqueología y Ciencias-, sin mengua de la Unidad nacional como lo expresa su denominación. Tiene un Museo curiosísimo. Existen, igualmente, el Museo Provincial, preparándole actualmente un alojamiento adecuado en la antigua Casa Consulado, la Academia Provincial de 
Bellas Artes y el Archivo Regional de Galicia, instalado provisicnalmente en la Audiencia Territorial y, por último, como exponente de nuestro folklore, el Orfeọn Coruñés "El Eco" y el Coro "Cántigas da Terra".

Desarrollo de la parte uRbana. Planes de REForma interior. PLANES DE ENSANCHE

\section{Estructura del núcleo urbano}

La Coruña cuenta con barrios de características diferenciales un tanto acusadas. Intentaremos destacar algunas:

Vaya en primer lugar la Ciudad Vieja o Alta, asiento del burgo primitivo. Contrasta con el resto de la población por la antigüedad de sus Iglesias, de notable mérito arquitectónico; por su topografía, con calles pinas; por sus restos de murallas que eran bastiones para guardar la defensa de la plaza; por las puertas abiertas en los muros que dan al mar, facilitando el acceso a la playa, y que en otro tiempo sirvieron de paso a personas reales para embarcar con rumbo al extranjero en momentos que registra la Historia.

De fecha reciente es la construcción de la Ciudad Jardín, que se levanta en las cercanías de la Playa de Riazor. La forman hermosos chalets, generalmente de dos pisos, rodeados de pequeños huertos con plantas de adorno. La variedad de las edificaciones, todas de depurado gusto, produce en el ánimo una gama de emociones. Las irregularidades del suelo han sido sabiamente aprovechadas para que todos los chalets disfruten de las mejores condiciones higiénicas.

El centro de la ciudad está a tono con la forma oblonga de ésta. El tráfico de las diversas calles y travesías desemboca y se encauza principalmente por tres grandes vías longitudinales.

Como pueblo eminentemente marítimo sus casas miran al mar, siendo fácil el acceso desde cualquier punto; estando bordeado por carreteras y calles que pasan a pocos metros de las aguas.

Se le llama a La Coruña la ciudad de cristal, y esto es debido a las galerías que ostentan todas las casas. Los balcones, que antes predominaban en los primeros pisos, van dejando sus sitios a los miradores. El cambio tiene fácil explicación: lo imponen los vientos que reinan una buena parte del año, la larga duración del invierno y 
el aprovechamiento y comodidad de la estancia. Es la galería nota característica de La Coruña, y el efecto que produce vista desde el mar es de luz y alegría.

La zona de ensanche está en gran parte ocupada por modernos edificios, amplios, elegantes. Son, en su casi totalidad, como los que van alzándose en iguales barrios de las demás ciudades, sin peculiaridad destacable.

Los soportales, de rancio sabor castellano, no se construyen ya. El mayor aprovechamiento del suelo lo impone. Se conservan, no obstante, en la Avenida de la Marina y en la amplísima plaza de María Pita, sede de la Casa Consistorial, que está cerrada por sus cuatro lados con edificios que guardan la misma estructura. Los soportales que la circundan son altos, comprendiendo con el piso bajo el entresuelo. La uniformidad de la plaza, con la excepción destacable del magnifico Palacio Municipal que da cierta prestancia, causa complacencia en los que la admiran.

\section{Planes de reforma interior}

Como reforma interior de la ciudad, La Coruña sufre, como otras ciudades, los inconvenientes, que se traducen en angustiosos problemas de congestión de tráfico, de calles estrechas y tortuosas en algunos puntos de su parte central. Existe, de bastantes años atrás, un plan de alineaciones que trató de corregir deficiencias; pero ese plan, que se va llevando a la práctica con cierta lentitud, resulta hoy día anticuado por la intensidad, en auge continuo, de un movimiento circulatorio que hay que encauzar en forma que dé curso fácil al tránsito de viandantes y al paso de vehículos.

Para aquellos sectores donde el peligro es más tangible, se han estudiado reformas traducidas en proyectos que van realizándose. Igual ocurre en otros lugares, también en el casco de la población, que bien por razones de orden higiénico o simplemente de índole urbanístico, demandan una modificación que llene aspiraciones como las de embellecimiento, sanidad, enlaces cómodos y racionales, y tantas otras, sin olvidar la creación de los justamente suspirados "espacios libres".

Entre los planes de reforma parcial ocupa el primer lugar la apertura de la calle de Durán Loriga, roturada en toda su latitud 
en casi la mitad de su largo. Concebida primero como calle cubierta, que sirviese de paseo invernal, se desechó pronto la idea por varias razones. En el trozo que está abierto se alza el palacio construído exprofeso para Delegación de Hacienda, cuyas oficinas se hallan instaladas cómodamente $y$ con sobria elegancia.

Otra calle cuya apertura se ha realizado recientemente, es la del Marqués de Pontejos, que facilita el acceso al Mercado de San Agustín. Esta vía ha solucionado varios problemas a la vez: evita rodeos, encauza el tráfico de carruajes cursando hacia núcleos de residencia a gentes que se aglomeran en un punto que marca distintas direcciones.

También existe para ejecutar - pues el proyecto hace poco que ha sido aprobado-, la prolongación de la calle llamada del Curro, en un tramo no muy largo, pero sí muy necesario, porque derribará construcciones antihigiénicas, algunas de las cuales dejarán el sitıo para vía pública y otras serán sustituídas por casas confortables.

Sin haberse llegado aún a concretar de un modo definitivo su longitud, se estudia la apertura de otra nueva calle, de trazado transversal, cuyos planos están ya confeccionados, entre làs dos vías más concurridas y más comerciales de la ciudad: la de San Andrés y Real. Puede decirse que está ya abierta en un trozo, pues han sido derribadas varias edificaciones, si bien esto lo realizó un particular con miras a dejar una amplia plaza ante su establecimiento industrial.

Como nota simpática reveladora de un espíritu delicado, hemos de mencionar la plaza del Marqués de San Martín. Más que incluirla entre los planes corrientes de reforma, puede considerársela como algo especial y selecto. Está situada delante de la iglesia de San Jorge y a pocos metros del suntuoso Palacio municipal. El proyecto de su total urbanización con arreglo a determinado estilo arquitectónico, es de hace pocos años. Para conservar el carácter de ambiente barroco que predomina en la plaza, se ha condicionado la edificación de fachadas de las casas, que habrán de sujetarse al proyecto que ha sido estudiado por los técnicos municipales. $Y$ ese proyecto se aplica rigurosamente en las construcciones que van alzándose en la parte Norte. Al Oeste se abre una amplia rotonda de losas de granito, circundada por una balconada, guardando sitio en el centro para el Crucero que será erigido.

El Ayuntamiento acaba de llevar a efecto últimamente el proyecto de reforma de lo que antes se conocía por el nombre de Campo 
de la Leña y se denomina ahora plaza de España, pavimentando las cuatro vías que la rodean, con sus aceras, dejando la parte central para ulterior estudio. De la amplitud de esta plaza dará una idea el hecho de que sólo la pavimentación de esas vías importa cerca de 600.000 pesetas. Las expropiaciones para lograr una total regularización y el establecimiento de enlaces cómodos con las calles próximas, están reservadas para nuevos expedientes que irán tramitándose según la urgencia.

Como colofón de estos proyectos que vamos citando a la ligera, pondremos el de la vía de enlace del andén de Riazor con el del Orzán y carretera de circunvalación. En junio de 1940 se aprobó por la Superioridad la parte que comprende una avenida que, bordeando la playa del Orzán, termina a inmediaciones del Matadero municipal, donde se une con la carretera citada. Ahora se trata de completar esa Avenida prolongándola hasta el andén de Riazor. Cuando sea realidad el proyecto existirá un amplio paseo de contorno de la ensenada del Orzán, en que sin obstáculos visuales se puedan admirar las dos playas - Riazor y Orzán - en todo su recorrido frontero al mar, desde la carretera de circunvalación, en su término, próximo al Matadero, hasta el espigón de Miramar. La longitud del actual trozo a urbanizar es de 500 metros y su anchura de 20 metros.

\section{Ensanche y urbanización}

Derruídas las murallas y suprimido el cinturón que comprimía a la antigua ciudad, se evidenciaba cada vez más la necesidad imperiosa de estudiar su ensanche, buscando la urbanización de aquellos parajes próximos y resolviéndose a la vez otros problemas de higiene, sanidad y carencia de viviendas para alquilar, etc., etc. Dieron comienzo los estudios en 1878 , y se aprobó el proyecto del primitivo ensanche por R. O. de 16 de noviembre de 1883 .

Dicho ensanche comprende dos zonas. La primera comienza al final de la Pescadería con la hermosa Avenida de Juana de Vega, que sustituyó al antiguo paseo de La Coruña llamado de la Alameda, que se extendía entre las murallas y la parte posterior de la calle de su nombre, desde la puerta de La Torre de Arriba a la de la Torre de Abajo. También comprende esta zona el antiguo y extenso campo del Carballo, donde está la plaza de Pontevedra y el Ins- 
tituto, etc., etc. La segunda zona se halla entre la calle de Juan Flórez y Linares Rivas, que ocupa las antiguas Huertas de Garás.

Posteriormente y habiéndose ejecutado ya bastante de dicho plan, se estudió y acordó su ampliación llevándose a efecto la aprobación del proyecto por R. D. de 24 de mayo de I9io, comprendiendo éste la continuación del anterior y otros lugares más a las afueras, aún pendientes de urbanización.

Naturalmente, rigen unas Ordenanzas especiales para dichas zonas; Presupuesto independiente con arreglo a la legislación general de ensanche y particular de este Ayuntamiento, y funciona la correspondiente Comisión de Ensanche.

El Ayuntamiento, ante el sinnúmero de dificultades con que constantemente está tropezando para ordenar la urbanización de la ciudad, ha acometido resueltamente el problema para darle satisfactoria solución encomendando a un técnico, ilustre arquitecto-urbanista, su proyecto de urbanización.

Se trata de un asunto de vital importancia para nuestra ciudad, reclamado insistentemente por el público y anhelado por los Concejos que de años atrás han venido sucediéndose y que por diversas causas no ha tenido solución hasta el momento presente. Abordarlo en su totalidad parecía empresa ingente, que requería la preparación de un plan de trabajo complicado y multiforme, redactado por técnicos especializados y de larga y costosa realización. $\mathrm{Y}$ así la magnitud de la empresa hacía que el remedio se fuese aplazando y con ello el mal se agravaba.

El esfuerzo particular, buscando un interés legítimo, no puede tener en cuenta el interés colectivo, sobre todo si ambos establecen pugna entre sí. Para armonizar las conveniencias de unos y las necesidades de otros están los Organismos a quienes las leyes señalan el cometido de procurar el bien común.

Barriadas enteras construídas sin líneas oficiales, sin rasantes racionales, sin medios de enlace para regularizar el tráfico, son hechos que están a la vista de todos y que hacen clamar por un plan general de ordenación donde no sólo se piense en la construcción de casas, sino en el complemento necesario de los distintos servicios que la vida demanda, con los imprescindibles espacios libres.

El Ayuntamiento coruñés quiso resolver el problema que le planteaba la experiencia de la ciudad, convocando un concurso de proyectos. La realidad demostró lo difícil que resulta lograr que los 
técnicos que acuden a estos concursos, trabajen directamente en la ciudad y estudien con la profundidad y detenimiento necesarios los problemas locales para buscarles soluciones acertadas que puedan considerarse en la práctica como viables; : porque ellos les llevaría, sin duda, a invertir más dinero del que pudieran conceder los premios, aun concebidos en términos de la mayor generosidad. El resultado de este concurso vino a demostrar que, en definitiva, el procedimiento no es otra cosa que un trámite dilatorio.

En vista de ello, el Ayuntamiento, al amparo de lo.dispuesto en el Reglamento de Obras y Servicios municipales, concertó directamente con el arquitecto don César Cort los siguientes trabajos:

I. ${ }^{\circ}$ Proyecto de vías arteriales con la documentación necesaria para su trámite y aprobación por la Superioridad.

2. ${ }^{\circ}$ Proyecto de detalle de dos intervías.

$3 .^{\circ}$ Plan general de normas comarcales para ordenar y dirigir la urbanización en toda la zona de influencia de La Coruña.

$4^{\circ} \quad$ Proyecto de reforma del alcantarillado actual,' además del que requiere el documento primero para el ensanche y extensión.

5. ${ }^{\circ}$ Proyecto de abastecimiento de aguas.

6. ${ }^{\circ}$ Proyecto del alumbrado público de gas y electricidad.

$7 .^{\circ}$ Ordenanzas de edificación de la ciudad y en los alrededores.

$8^{\circ}$ Pliego de condiciones facultativas para las obras de urbanización comprendidas en los proyectos.

9. ${ }^{\circ}$ Estudio para el mejoramiento de la recogida, transporte y tratamiento de basuras.

Io. Estudio económico de la expansión de la ciudad y medios necesarios para llevarlo a cabo y orden de prelación de las obras.

Todos estos documentos están casi terminados y la Corporación en vísperas de recibirlos oficialmente, expondrá al público el Proyecto sometiéndolo a la tramitación ordenada.

\section{LA VIVIENDA \\ Clase dominante}

El tipo corriente de casa en $\mathrm{La}$ Coruña y su término municipal se difierencia según la zona en que esté situada.

La clase dominante en el casco de la población es la de cuatro plantas, destinándose el bajo a negocio y los pisos a viviendas; las 
Gimensiones oscilan entre 5 y 7 metros de frente con fondo de I2 a 14 metros y superficie cubierta media de 75 metros cuadrados; la ciistribución es rudimentaria, trazada por propietarios o maestros de obras ateniéndose al aprovechamiento utilitario del espacio disponible, con exclusión de elementales normas de salubridad; sólo dispone de un patio posterior, en prolongación del solar, al que asoma una galería acristalada; un largo y oscuro pasillo da acceso a todas ias dependencias que al interior están en segundas y terceras luces o en penumbra y con un simple maivel de ventilación. Dispone de sala, cuatro o cinco alcobas, comedor, cocina y retrete, siendo la altura libre de unos 2,60 metros; el promedio de habitaciones es de seis en cada vivienda.

La tercera parte de estas casas cuyos pisos han sido reformados o ampliados reune mejores condiciones de habitabilidad desde que la autorización de las obras se acondiciona al cumplimiento de Ordenanzas, dirección facultativa e inspección sanitaria.

En la zona de ensanche, en que la mayor parte de la edificación se ha realizado conforme a Ordenanzas especiales, el tipo dominante de viviendas se compone de sala, un amplio dormitorio con gabinete para matrimonio, dos dormitorios individuales para ambos sexos y uno aparte para el servicio, cocina, comedor, cuarto de baño y vestíbulo; la capacidad media es para cinco personas; en este tipo de casa se ha omitido, generalmente, los patios interiores de iluminación y ventilación, por razón de economía y por ser autorizadas las habitaciones en segundas luces.

Las dimensiones mínimas del solar son de 8 metros de frente por 13 metros de fondo, con forma regular y superficie de roo metros cuadrados. La altura libre en los pisos es de 3 metros.

Predomina la casa de cinco plantas con bajo para tienda, almacén o garaje y son escasas las viviendas que disponen de ascensor y calefacción, aun cuando la tendencia es irlos implantando cada vez más.

En el extrarradio, la casa corriente es de dos plantas, y en zona semi-rural, de una, con capacidad para cinco habitantes, disponiendo rle sala, tres dormitorios, cocina y retrete. 


\section{Casa familiar o casa por pisos}

Son escasos los edificios de dos o más viviendas en cada planta que, en todo caso, no difieren en su distribución y capacidad de la clase de dominante a excepción de que disponen de portería, ascensor, patios interiores y son de seis o siete plantas. No obstante, en las nuevas construcciones del ensanche y con el fin de obtener mayor rendimiento a los solares, la tendencia también es la de construir casas por pisos, con dos o tres en cada planta.

$\mathrm{El}$ número de edificaciones destinadas a viviendas en el término municipal se eleva a 10.200 , dedicadas a este fin y otros usos, siendo su distribución en la forma siguiente: Número de pisos, I6.400; viviendas unifamiliares, 4.050 ; viviendas plurifamiliares, 5.030. Con jardín o huerta, 2.510; con corral adosado a ellas, I.500; casas baratas y económicas, 86 ; y viviendas inhabitables, I60.

Las buhardillas, que se conservan aún en las casas antiguas, no se construyen ya, y su lugar lo ocupan pisos áticos con azoteas.

Es la galería nota característica de La Coruña, como antes decimos, y es una lástima que en las modernas construcciones se prescinda de ella, adoptando ese tipo uniforme y corriente en otras poblaciones.

\section{Número de pisos más corrientes en edificaciones}

Como queda dicho, en el casco de la población el número de pisos más corrientes dedicados a vivienda es de tres, en el ensanche de cuatro, en el extrarradio de dos y en la zona semi-rural de una planta baja.

Variaciones en la materia, si ha habido en las Ordenanzas municipales

Las Ordenanzas municipales disponen que cada vivienda se formará de un dormitorio de matrimonio y dos individuales, cocina y comedor, aparte del retrete, todo con entrada independiente y fijan las superficies y volúmenes adecuados a cada dependencia. Dichas Ordenanzas, no han sufrido, en esencia, más modificaciones que las 
transitorias, de carácter general, que periódicamente emanan del Mínisterio de Gobernación, pero manteniéndose la vigencia de las mismas, desde su aprobación en 1903, si bien se ha venido permitiendo una mayor altura en la edificación, levantándose en la parte próxima al mar o en las nuevas plazas, modernos "rascacielos", de más de 20 metros, por imponerlo así el mayor aprovechamiento del suelo, dado el enorme coste de los solares.

¿ES FRECUENTE EL AUMENTO DEL NÚMERO DE PISOS EN CASAS ANTI-
CUADAS?

Datos respecto a tales hechos

Exceptuando la denominada Ciudad Vieja, todo el casco de la población, de antiguo edificada y carente de solares, se ha ampliado contínuamente en sentido vertical. El frecuente aumento del número de pisos en casas anticuadas es efectivo y se debe al hecho de que las actividades oficiales, comerciales, etc., se concentran en el centro de la población.

La protección oficial del inquilino que se aferra al módico alquiler y también la dificultad de desalojar los inmuebles debido a la penuria de la vivienda, impide que el número de obras de ampliación y reforma se realice a un ritmo considerablemente mayor; en cambio, al amparo de la Fiscalía de la Vivienda, se ejecutan con mayor frecuencia pequeñas obras de adaptación para mejorar, circunstancialmente, las mínimas condiciones de habitabilidad en los pisos de casas antiguas y esta clase de arreglos es favorecida por el empleo de poco material, de muy difícil adquisición hoy día para obras de mayor importancia.

\section{VIVIENDAS BARATAS}

\section{Del "Campo de Marte"}

Acogiéndose a la ley de 12 de junio de I9I I, la Sociedad "Cooperativa de casas baratas de La Coruña", solicitó en diciembre de 1920, la concesión de terrenos y una subvención para construir casas baratas en número de 24 . 
El Ayuntamiento, en I4 de febrero de I92I, acordó ceder a tal efecto terreno en el "Campo de Marte".

La superficie de cada una de las veinticuatro casas citadas es de i $16,50 \mathrm{~m}^{2}$, sumando la de la totalidad $2.796 \mathrm{~m}^{2}$.

En 23 de abril de 1924 el Ayuntamiento cedió terreno a la citada Sociedad para ampliar las veinticuatro construcciones proyectadas, en una superficie de 70 centímetros en el sentido de fondo.

De informe emitido por la Sección Técnica municipal resulta que las veinticuatro casas se agrupan en manzanas de seis casas, siendo la superficie de cada manzana $741,70 \mathrm{~m}^{2}$ y la de todas $2.966,80 \mathrm{~m}^{2}$

\section{Casas baratas de "Domus"}

En febrero de 1935 la Sociedad Cooperativa "Domus" notíncó que se proponía construir un grupo de chalets para viviendas de sus socios, en número no inferior a treinta, y proyectando edificarlos en la Ciudad Jardín solicitaba del Ayuntamiento procediese a la apertura y urbanización de las calles $3 \cdot{ }^{\mathrm{a}}$ y $4 \cdot^{\mathrm{a}}$ longitudinal y del Paseo de Ronda.

En junio de 1935 la misma Sociedad presentó proyecto para construir quince grupos de dos casas gemelas y solicitó exención de derechos municipales. Anunciaba que las construcciones se levanta. rían acogiéndose a los beneficios del $\mathrm{R}$. D. de 29 de julio de 1925, convertido en Ley en 9 de septiembre de 1930.

En la "Gaceta" de 23 de noviembre de 1935 se publicó una Orden de Trabajo aprobando los terrenos para las construcciones y calificando condicionalmente el proyecto de treinta casas familiar económicas que proyecta construir "Domus", a los solos efectos de las exenciones tributarias durante quince años.

El Ayuntamiento autorizó la construcción, eximiéndole del pago. de derechos.

La edificación ocupa un área de 72 metros cuadrados. Son casas tipo chalet y tienen jardín. Consta cada uno de dos plantas y desván. 


\section{Viciendas protegidas "Juan Canalejo"}

En sesión plenaria de 30 de diciembre de 1493, el Ayuntamiento aprobó el proyecto de viviendas protegidas "Juan Canalejo", señàlándole como emplazamiento el lugar de Nelle.

Consta el proyecto de 400 viviendas y un edificio social para Hogar Sindical.

Son tres los tipos de viviendas que integrarán el grupo:

Tipo A.-Viviendas gemelas de dos plantas.-Constarán de dos dormitorios de dos camas, uno de tres y otro de una; sala de estar, comedor, retrete, baño, despacho, cocina y ropero.

Tipo B.-Viviendas gemelas de planta baja.-Se compone cada vivienda de dos dormitorios de tres camas, uno de dos y otro de una; sala de estar-comedor, cuarto de baño y cocina.

Tipo C.-Viviendas en línea de planta baja.-Se compone de las siguientes dependencias: tres dormitorios de dos camas, sala de estar-comedor, cocina y cuarto de aseo.

Según oficio de la Jefatura del Movimiento, el presupuesto protegiclo total asciende a $16.011 .832,60$ pesetas.

Dicho proyecto lo llevará a efecto la Obra Sindical del Hogar, subvencionándolo el Ayuntamiento con la cantidad de I50.000 pesetas y urbanizando también las calles colindantes.

Ultimamente nos enteran de que una importante Entidad Benéfica se dispone a construir un número crecido de viviendas para gentes humildes, con objeto de librarlas de los locales y chozas inmundas, donde por necesidad se cobijan.

En el Presupuesto extraordinario pendiente de aprobación consigna el Ayuntamiento cinco millones de pesetas para la construcción de viviendas protegidas en el término, con inclusión preferente de un grupo para pescadores a inmediaciones del "Portiño", en la falda del Monte San Pedro, y otro para empleados y obreros municipales. Este no se ha hecho, pero es necesario construir muchas más vivien- 
das baratas y ultrabaratas para familias modestas, obreros y pobres, a fin de que desaparezcan esos tugurios que aquí se llaman "ranchos", y de que las viviendas puedan ser habitadas realmente sólo por el número de personas que constan en la Cédula de habitabilidad, con lo cual gana la Patria, la moral, la higiene y la raza, y se llevaría la alegría, por el amor y la comprensión, a tanta gente desamparada.

Alejandro Rebollo

\section{Publicaciones del Instituto de Estudios de Administración Local}

Acaban de aparecer:

\section{CONTRATOS ADMINISTRATIVOS \\ POR \\ Recaredo Fernández de Velasco}

Edición-homenaje al malogrado Catedrático de Derecho Administrativo y Profesor de la Escuela Nacional de Administración y Estudios Urbanos.

2. ${ }^{a}$ edición: Concordada y puesta al día por los Sres. D. José Gascón y Marín y D. Eduardo Leira Cobeña.

Un volumen de 416 págs.: Precio 35 pesetas.

\section{ESTUDIOS Y ESTADISTICAS DE LA VIDA LOCAL DE ESPAÑA}

Tomo IV.-Adiministración Municipal.

Volumen III.-Municipios de población inferior a 15.000 habitantes.

A.-Población. Servicios.

Un volumen de 554 páginas, con profusión de gráficos, encuadernado: Precio Ioo pesetas.

EXPLOTACION DE SERVICIOS.-2. ${ }^{\circ}$ CURSO

VIALIDAD Y SANEAMIENTO POR

José Paz Maroto

Un volumen de 200 páginas, profusión de grabados y cinco croquis: Precio 35 pesetas.

Diríjanse los pedidos a la Sección de Publicaciones del INSTITUTO DE ESTUDIOS DE ADMINISTRACION LOCAL García Morato, 7.-Madrid. 